GLACIAL EPOCHS OF THE SANTA MONICA MOUNTAINS. CALIFORNIA

\author{
By W. M. Davis \\ California Institute of Technology \\ Communicated September 28, 1932
}

Situation and Physiography.-The four Santa Barbara Islands of southern California are aligned from west to east toward a land-bound member of the same series of upheaved masses, which constitutes the Santa Monica Mountains and which, with a length of 45 miles and a width of 10 or 15 , reaches inland to Los Angeles, LA, figure 1. These mountains consist, according to Hoots, ${ }^{1}$ of deformed Mesozoic and Cenozoic rocks, upfolded in mid-Miocene time. They were then greatly worn down before being broadly upheaved, along with a belt of weak and little deformed upper Miocene beds adjoining on the south, to altitudes of 2000 or 3000 feet in mid-Pleistocene time, in consequence of which they are now deeply dissected, and the belt of weak Miocene beds, much narrowed, is reduced to low relief. The western 30 miles of the southern mountain slope are bordered by the Pacific; there the shoreline is followed below the high-clift ends of the mountain spurs by a fine state highway of recent construction, much traveled as it avoids the heavy grades of roads farther inland.

At the middle of this 30 -mile coastal stretch three small ledges of resistant (volcanic?) rock, the eastern one the lowest, the middle one which rises over 200 feet the highest, stand forth in Point Dume, two miles outside of the general shoreline. Back of them a triangular area of the weak Miocene beds, figure 2 , measuring 4 miles along its inner, piedmont side, survives the abrasion that has, to the west and east, consumed nearly all that belt and clift the more resistant mountain rocks behind it, some of the cliffs slanting up to a height of 500 or 600 feet. The state highway crosses the triangular area over a 200 -foot summit, and its fresh cuts give several clear rock exposures which demonstrate that, before the present epoch, there were two earlier epochs of coastal abrasion, the platforms of which, one now 140 feet, the other, figure 6, 200 feet above sea level, here truncate the gently inclined Miocene beds of the triangle. Occasional boring molluscs, as well as thin veneers of marine cobbles and sands, figure 7 , under a cover of subaerial detritus, attest the former presence of the sea.

Three Epochs of Sea Advance.-It thus appears that the Santa Monica coast has suffered three abrasional attacks at different levels by the advancing waves, and the platforms which record these abrasional attacks may be named, in order of height and of time, Malibu (uppermost), after an extensive coastal estate, Dume (middle), after the above-mentioned point, and Monic (present shore), abbreviated from the name of the moun- 
tains and of the broadly abraded bay south of them. The Malibu and the Dume platforms are so well shown in the Point Dume triangle that, in spite of the small lengths of the exposures there and in spite of the advanced consumption of the earlier platforms elsewhere by the abrasional retrogradation of the later one, even a hasty observer must recognize their original extension all along the coast. Only one other exposure of the Malibu platform has been found in a western segment of the coast between Sycamore and Sequis creeks, figure 1; and only very short and far-separated exposures of the Dume platform are found to the east and west of Point Dume.

The manifest reason for the better preservation of the earlier platforms

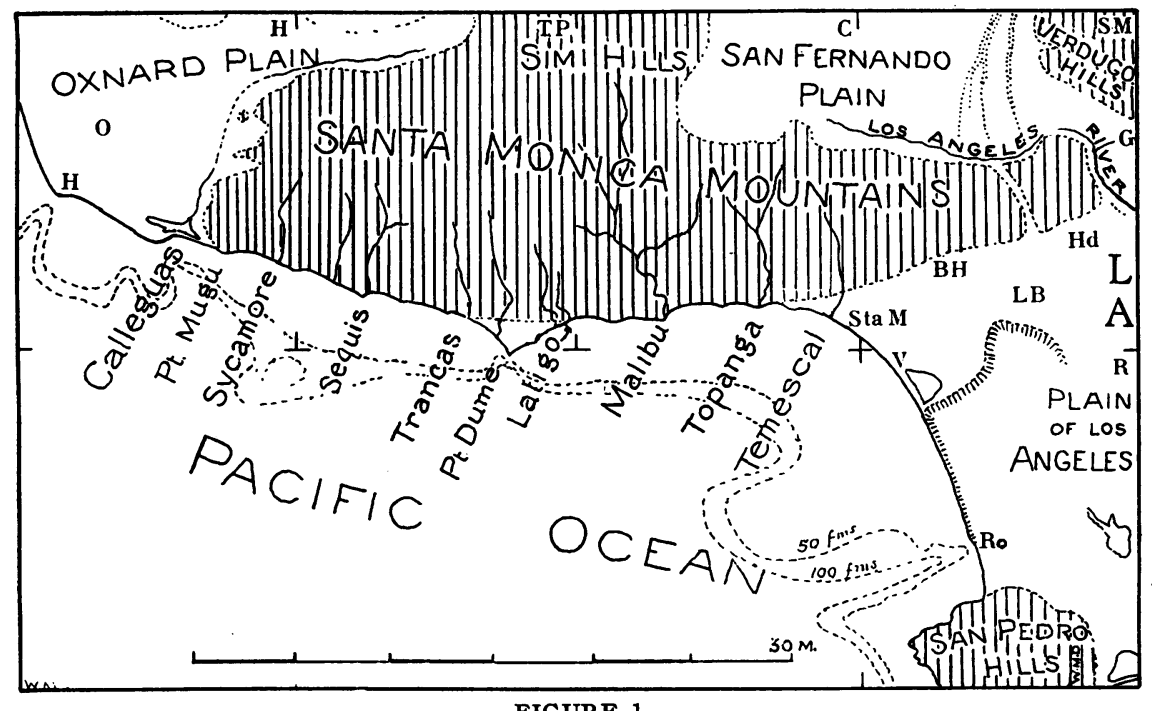

Outline map of the Santa Monica Mountains, California.

in the Point Dume triangle is that the Monic cliffs are there held off by all three of the outstanding ledges from consuming the Dume platform above and back of them, as in figure 2; while the Dume cliffs, escaping detention of the low eastern ledge, and receding 800 feet in cobark* outline back of the high middle ledge, but detained on the western ledge, leave a considerable area of the Malibu platform back of and above them, shaded with broken lines in figure 2 . Back of this area the Malibu cliffs, greatly subdued since their abandonment by the sea waves, reached an advanced cobark stage a long mile behind the middle ledge, so that their now rounded hills of Miocene beds survive only in a quarter of the present triangular area.

* Cobark is a new term, made up of the initials of its equivalent phrase, cut-out-behinda-rock-knob, after the fashion of cabal and Anzac. 
Two Glacial Epochs of Sea Withdrawal.-Two epochs of sea withdrawal and platform emergence must have alternated with the three epochs of sea advance and platform abrasion; and with the two epochs of withdrawal were associated small uplifts of the mountain mass. Furthermore, during the epochs of sea withdrawal, when the abraded platforms overstrewn with thin, wedge-like deposits of marine detritus were laid bare as infantile coastal plains, the plains were overspread (where they were not trenched by the larger extended streams) with subaerial detritus outwashed by the smaller streams and down-crept from the spur-end cliffs and from the mountain slopes above them. These deposits, which fill the dihedral or shoreline angle between cliffs and platform, constitute the Budu and the Memo covers of the platforms, their names being formed from the adjoining syllables of the three, abrasional-epoch names. When the covers are cut back and clift their remnants, behind which the rock cliffs are concealed, will be called cover-heads.

Along the western 10 miles of the coast the Dume shoreline stands 25 or

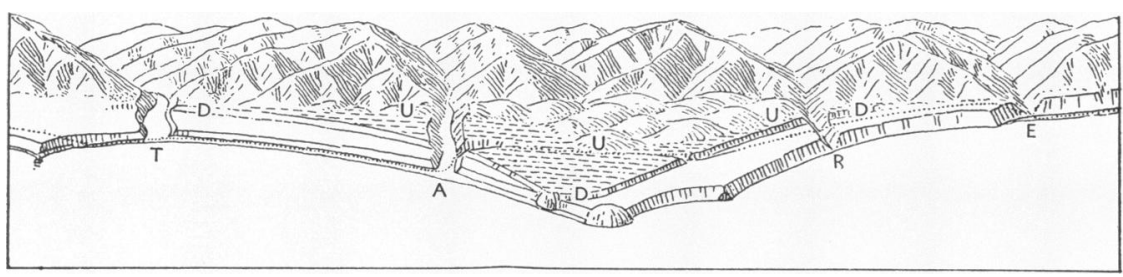

FIGURE 2

Simplified diagram of the Point Dume triangle. $U, U, U$, weathered cliffs of Malibu shoreline; $D, D, D$, cliffs of Dume shoreline. $T, A, R, E$, Trancas, Zuma, Ramera and Escondido creeks.

30 feet above present sea level. The Memo lowering and withdrawal of the sea from that shoreline and the Monic rise and advance of the sea to the present shoreline are best explained, following Daly, ${ }^{2}$ by the waxing and waning of a late Glacial epoch; the change of level may have been 250 or 300 feet. The failure of the sea to return now to its former or Dume level is apparently due to the lower temperature of the present Postglacial epoch, in which ice-sheets linger on Greenland and in Antarctica, as compared to that of an earlier and warmer, Interglacial epoch. To be sure, the Memo withdrawal and the Monic return of the sea might be ascribed to an uplift and a depression of the land; but that would in the first place require a depression about equal to the previous uplift, which is inherently improbable, and would in the second place leave out of account the unquestionable changes of sea level due to Glacial variations of climate, the equable nature of such changes of level being their most essential characteristic. But the gradual rise of the Dume shoreline from a 25- or 30-foot 
altitude in the western 10 miles of the coast to 140 feet at Point Dume and to 250 feet or more in the easternmost coast must manifestly be explained by an eastward-increasing uplift of the mountain mass. This uplift presumably took place in Memo time, before the return of the abrading Monic sea.

The Budu withdrawal and the Dume return of the sea are likewise best explained by the waxing and waning of an earlier Glacial epoch. The uplift of the coast therewith associated appears to have increased from a small measure at Point Dume to about 170 feet farther west.

The Gratifying Features of Confirmation Bight.-A strongly clift, interheadland bight, figure 3, in the Sycamore-Sequis coastal segment, figure 1, confirms the sequence of events inferred from the road-cuts in the Point Dume triangle in the most gratifying manner, and also affords some additional information. In the first place, the survival here of the Budu and

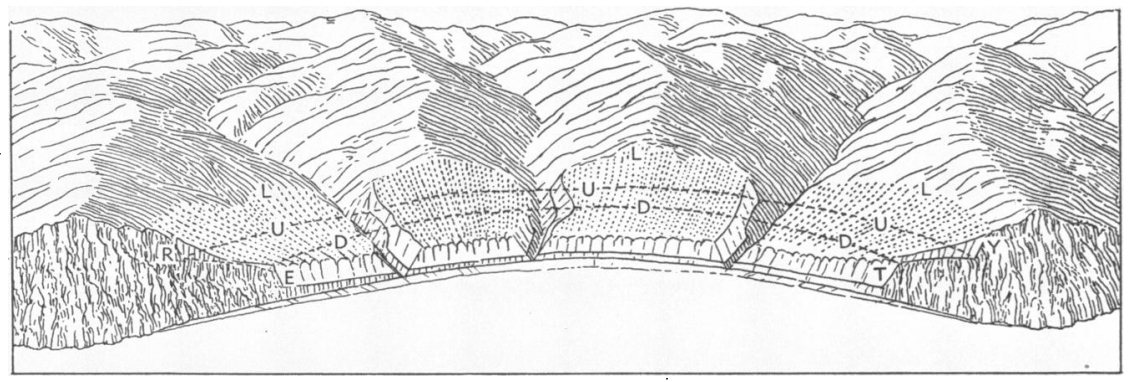

FIGURE 3

Idealized diagram of Confirmation Bight. $E, T$, entrance and exit sections of Dume cliffs; $R, Y$, entrance and exit sections of Malibu cliffs. $D, D, D$, top of Dume cliffs under their Memo cover. $U, U, U$, Malibu shoreline under its Budu cover. $L, L, L$, weathered Malibu cliffs over head of Budu cover.

Memo cover-heads across the middle half-mile of the bight, while the covers are completely cut away in the Monic cliffs of the bold, bight-limiting headlands, show that the Malibu shoreline was more sinous than the Dume and the Dume more sinous than the Monic. When this was perceived it was seen also that the Malibu and the Dume cliffs and platforms must be concealed behind and beneath the cover-heads, and after persistent search they were duly found. A small high-standing exposure of the Malibu platform occurs in a ravine where steeply inclined, resistant and well truncated, mountain-making strata bear a veneer of cobbles under a cover of subaerial detritus at an altitude of about $160 \mathrm{feet}$; and as the mountain slope begins a rapid ascent to a much greater altitude a little way farther inland, the Malibu cliff-base shoreline, concealed by its Budu cover, is inferred to have an altitude of somewhat less than 200 feet at the foot of that slope. 
Several low-lying exposures of the Dume platform are found along the shore under its heavy and strongly clift Memo cover-head which, blending with the degraded Budu cover above and back of it, must have a thickness of 200 or 300 feet near the concealed Dume cliffs. One beach exposure of the platform, figure 8 , shows a striking contrast between vertical, truncated, mountain-making strata and their level-bedded, indurated veneer of marine sands and cobbles. Moreover, inasmuch as the Memo cover-head, occupying the middle half-mile of the bight, must stand between the concealed Dume cliff behind it and the visible Monic cliff, refreshed in the way-side

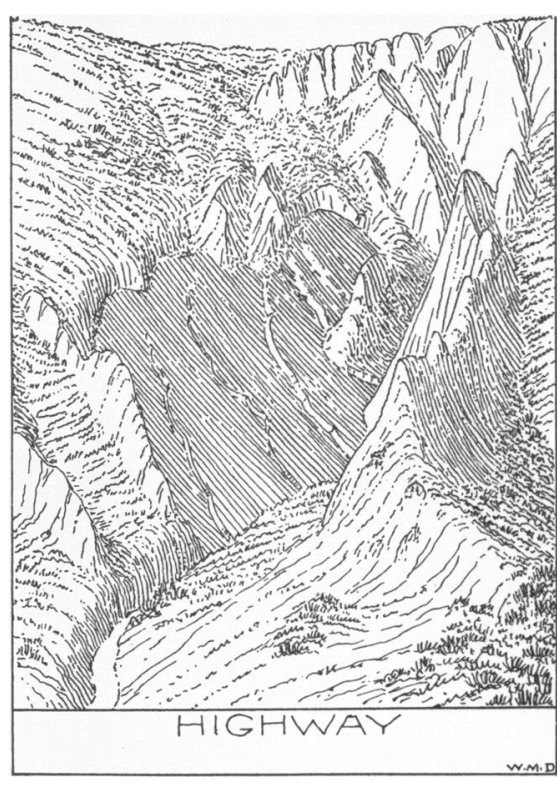

FIGURE 4

The Dume cliff face in a ravine-head of Confirmation Bight.

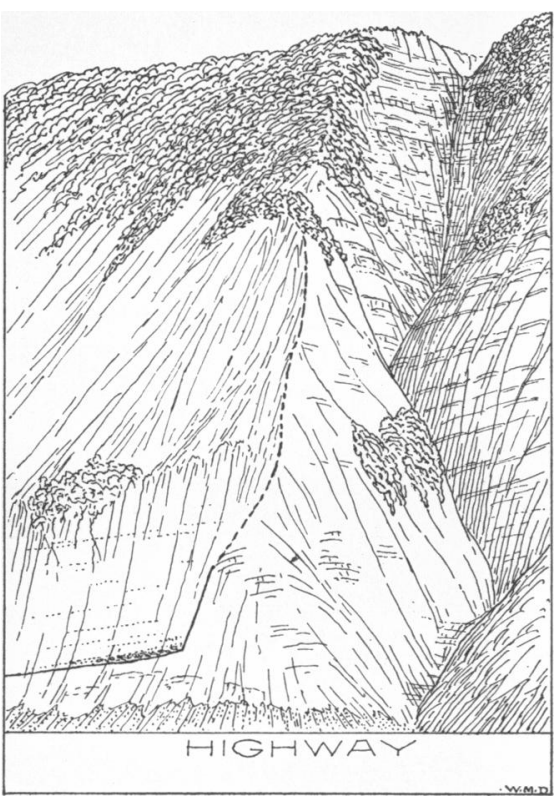

FIGURE 5

Exit section of the Dume cliff with its platform, Confirmation Bight.

cut of its front face, sections of the Dume cliffs should be seen where the clift rocks of the headlands are adjoined by the clift detritus of the coverhead; one, $E$, figure 3 , showing the oblique entrance of the cliff into the bight back of the cover-head; the other, $T$, its oblique exit.

Both have been found. The entrance section does not reveal the base of the cliff, because the highway bench, which is there rather high above the beach, conceals it; but the exit section, figure 5 , where the highway is a little lower, shows, although obscured by downwashed silt, not only the cliff to a height of perhaps 80 feet, but also the shoreline angle at the cliff base and some 50 feet of the platform with a veneer of marine gravels and 
cobbles, the angle between cliff and platform being heavily filled in with Memo detritus. Three additional exposures of the Dume cliff face, one of which is drawn in figure 4 , are made where ravines near the entrance and exit sections have removed the Memo cover. I have given this mile of the shore the name, Confirmation Bight, because its highly significant features were found, not by wandering observation before a theoretical analysis of coastal development had been made, but by directed observation after it had been made. Entrance and exit sections of the Malibu cliffs, $R, Y$, figure 3 , have been searched for high on the Monic cliffs of the headlands but not found; they are presumably hidden under creeping detritus.

Additional Items.- - To the west of Sycamore Creek no records of the Malibu interval and only a few imperfect records of the Dume-Memo interval have been found, because the recession of the Monic cliffs there is so strong as to consume the work of the earlier intervals. No record of the Malibu interval has been found east of the Point Dume triangle, but several good sections of the Dume platform and its Memo cover have there been identified at eastward-increasing altitudes.

Beyond the eastern end of the coast as limited by the Monic cliffs of Santa Monica Bay excavated in the uplifted Dume platform, the Memo platform cover, with a mountain-border thickness of 200 or 300 feet, extends eastward along the base of the mountains for 10 miles or more as a sloping, piedmont, detrital plain, dissected by many ravines. An excellent airplane view of the northwestern part of this area is given in one of Hoots' plates.

At three points along the coast indications are found of a subordinate withdrawal and return of the Monic sea, suggesting a brief Glacial episode rather late in the Monic interval. No space for their description can be given here.

Glacial Chronology of the Coast.-Although the Budu and the Memo withdrawals of the sea are confidently believed to mark the on-coming of two Glacial epochs, it must be understood that no record whatever of actual glaciation is to be found on the Santa Monica Mountains; they are far too low for such records, of which the nearest examples, the southernmost in California and the United States, are found at a much greater altitude

\section{DESCRIPTION OF Figures 6,7 AND 8}

Figure 6.-Road-side section of the Malibu platform truncating inclined Miocene beds, with veneer of marine cobbles and sands under Budu cover of subaerial detritus. Height, about 15 feet. Point Dume triangle. Photo by U. S. Grant, 4th.

Figure 7.-Detail of same. Photo by J. H. Maxson.

Figure 8.-Detail of Dume platform on beach of Confirmation Bight; vertical strata truncated and covered by an indurated veneer of marine coḅbles and sands. Photo by U. S. Grant, 4th. 


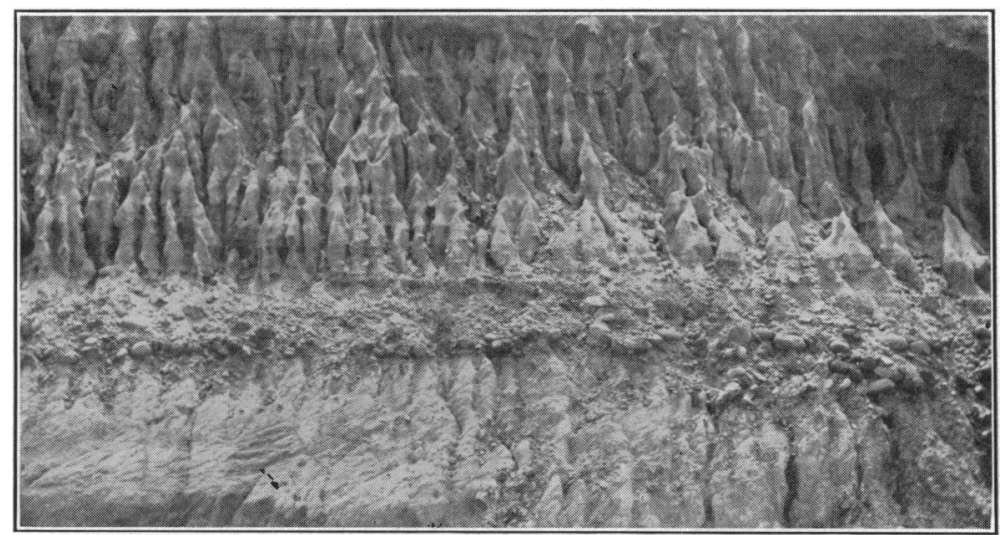

FIGURE 6



FIGURE 7

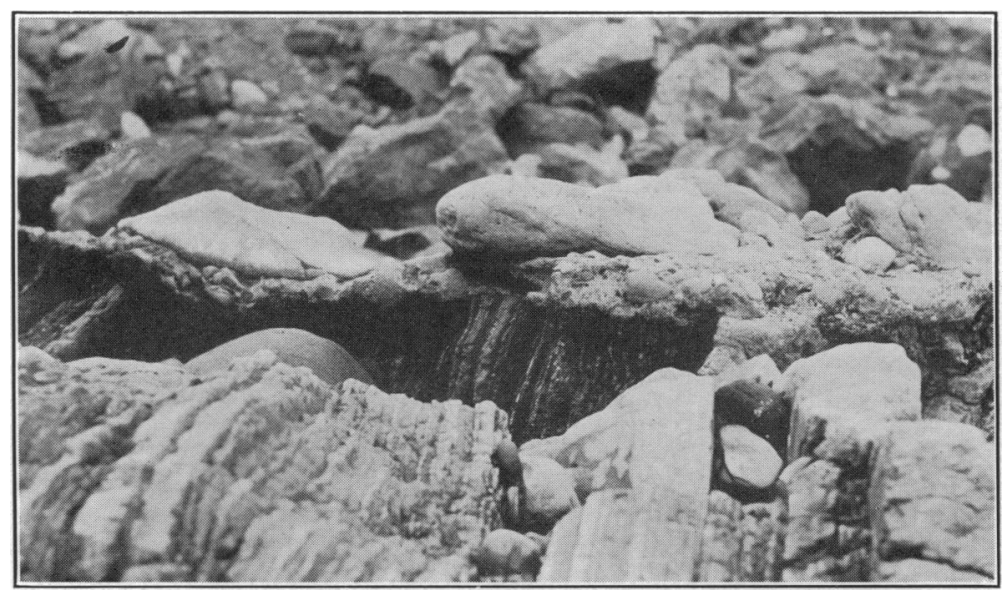

FIGURE 8

(For description of figures see opposite page.) 
in the San Gabriel and the San Gorgonio mountains about 40 and 90 miles to the east. But when it comes to matching the Glacial epochs of the coast with those of the Sierra Nevada as lately studied by Blackwelder, ${ }^{3}$ or of the northeastern United States, difficulty is encountered. A simple solution of the difficulty would be to equate the Budu coastal epoch with the next-to-last Glacial epoch, the Tahoe stage of the Sierra Nevada; and the Memo coastal epoch with the last Glacial epoch, the Tioga stage of the Sierra; but that stage seems too brief for the accumulation of the heavy Memo cover, and too recent to be followed by the great abrasional excavation of Santa Monica Bay by the advancing Monic waves. If escape from this embarrassment is sought by shifting the Budu and the Memo intervals back to the Sherwin and Tahoe stages of the Sierra Nevada, then the coastal record of the late Monic episode of sea withdrawal and return seems too brief to correspond even to the short-lived Tioga stage. The glacial chronology of the coast is therefore left uncertain for the present.

[A fuller discussion of the problem here outlined will shortly appear in the Bulletin of the Geological Society of America.]

${ }^{1}$ W. H. Hoots, "Geology of the Santa Monica Mountains, California," U. S. Geol. Surv., Prof. Paper 165 C (1930).

${ }^{2}$ R. A. Daly, "Swinging Sea Level of the Ice Age," Bull. Geol. Soc. Amer., 40, 721-734 (1929).

${ }^{3}$ Eliot Blackwelder, "Pleistocene Glaciation of the Sierra Nevada," Bull. Geol. Soc. Amer., 40, 865-922 (1931).

\title{
THE COMMUTATOR SUBGROUP OF A GROUP GENERATED BY TWO OPERATORS
}

\author{
By G. A. Miller \\ Department OF Mathematics, University of Illinois
}

Communicated October 3, 1932

Suppose that the group $G$ is generated by the two operators $s$ and $t$, and consider the commutators formed by powers of $s$ and $t$. These commutators are of the form $s^{\alpha} t^{\beta} s^{-\alpha} t^{-\beta}$ and if we transform such a commutator by $s$ or by $t$ there obviously results an operator which is the product of two such commutators or of inverses thereof. It therefore results that the group generated by the commutators of the powers of $s$ and $t$ is an invariant subgroup $C$ of $G$. The group generated by $C$ and $s$ is invariant under $t$ and its quotient group with respect to $C$ is composed of invariant operators under $t$. Hence $C$ is the commutator subgroup of $G$. That is, if a group is generated by two operators its commutator subgroup is generated by the commutators of the powers of these operators in order. 